\title{
A Word Communication System with Partner Assist for Amyotrophic Lateral Sclerosis Patients in Late Stages
}

This paper was downloaded from TechRxiv (https://www.techrxiv.org).

\section{LICENSE}

CC BY 4.0

SUBMISSION DATE / POSTED DATE

06-09-2021 / 09-09-2021

\section{CITATION}

Ozawa, Kuniaki; Naito,, Masayoshi; Tanaka, Naoki; Wada, Shiryu (2021): A Word Communication System with Partner Assist for Amyotrophic Lateral Sclerosis Patients in Late Stages. TechRxiv. Preprint. https://doi.org/10.36227/techrxiv.16573331.v1

$\mathrm{DOI}$ 


\section{Supplementary Material}

In this supplementary section, we show data that are not presented in the manuscript and help readers follow our experiments.

\section{S1. The Results of the Word-Expression Experiments}

We show the results of subject $B$ - subject $E$ in this section (The results of subject $A$ are shown in Fig. 4).
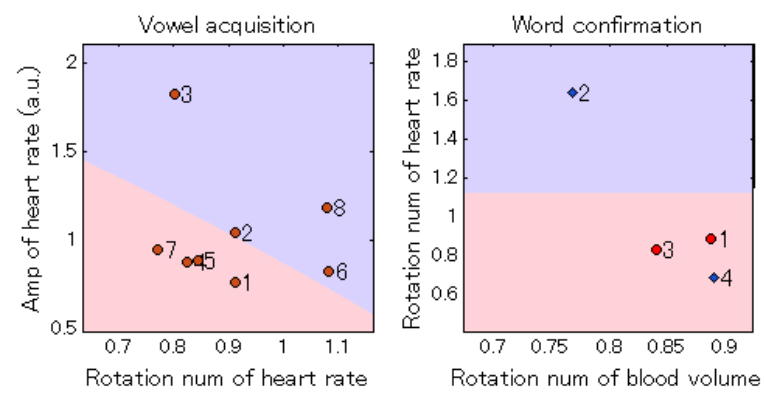

Subject B
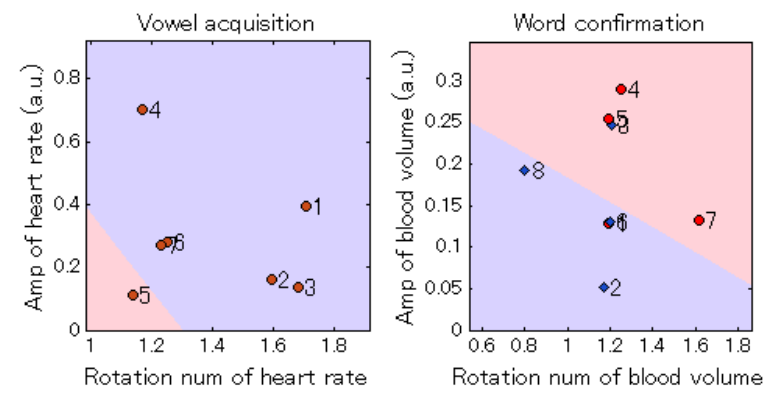

Subject D
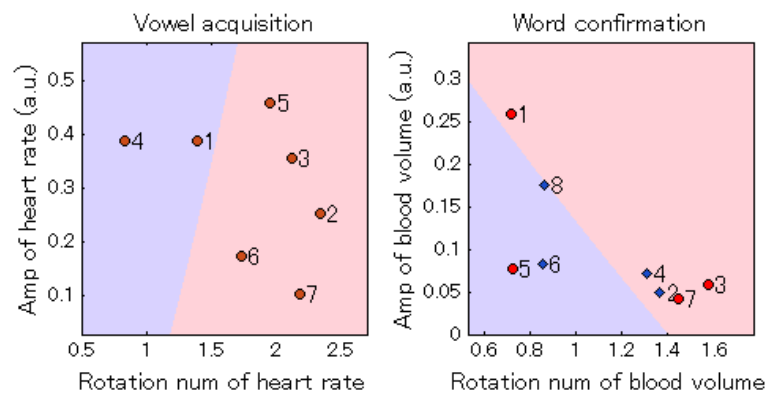

Subject C
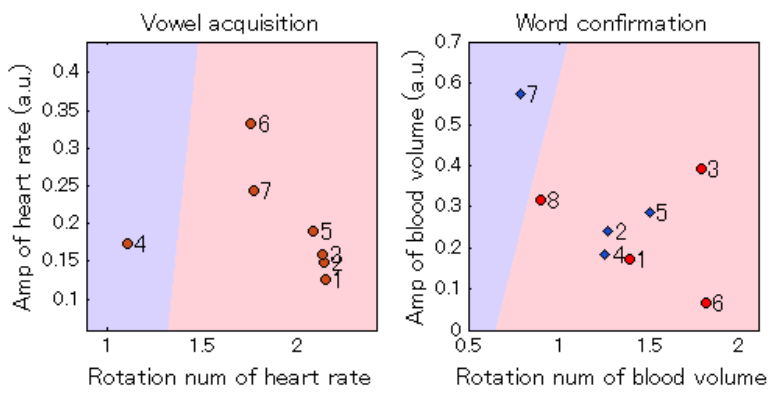

Subject E

Fig. S1. Feature vectors. The pink regions represent "yes" and the light purple regions represent "no." In the figures of word confirmation, the red circles represent "yes" answers to the affirmative question, while the blue diamonds represent "no" ans wers to the negative question. Thus, the red circles in the "yes" region and the blue diamonds in the "no" region are regarded as affirmative.

Table S1.1.

"Yes/no" answers and corresponding vowels in the vowel acquisition, and the vectors regarded as affirmative answers in the word confirmation. The numbers represent the vector number in Fig. S1.

\begin{tabular}{|c|c|c|}
\hline Subject & "Yes/no" answers and vowels & Affirmative vectors \\
\hline B & | “1-yes,” "2-no,” “3-no” (U) | “4-yes,” “5-yes” (A) | “6-no,” “7-yes”, “8-no” (O or NN)| & $1,2,3$ \\
\hline $\mathrm{C}$ & | “1-no,” “2-yes,” (E) | “3-yes,” “4-no,” “5-yes,” (I) | “6-yes,” “7-yes” (A) | & $1,3,6,7,8$ \\
\hline $\mathrm{D}$ & | “1-no,” “2-no,” (O) | “3-no,” “4-no,” (O)* | “5-yes,” “6-no,” “7-no” (U) | & $2,4,5,6,7,8$ \\
\hline $\mathrm{E}$ & | “1-yes,” “2-yes,” (A) | “3-yes,” “4-no,” “5-yes,” (I) | “6-yes,” “7-yes” (A) | & $1,3,6,7,8$ \\
\hline
\end{tabular}

* In the acquisition of ' $\mathrm{O}$ ' as the second vowel, corresponding sequence of "yes/no" is \{"no," "yes," "no"\} according to Fig. 2. However, the sequence is simplified to \{"no," "no" $\}$ when the partners are convinced that an expressed word contains at least two vowels. In that case, (End) is excluded from the second position. This situation is the same as that of the acquisition of ' $\mathrm{O}$ ' at the first position. 
Table S1.2.

Parameters in the word confirmation.

\begin{tabular}{cc}
\hline \hline Subject & Parameters (SVM training data, side of forehead, feature set, time window) \\
\hline $\mathrm{B}$ & original, right, $1,0-16 \mathrm{~s}$ for the heart rate and $3-19 \mathrm{~s}$ for the blood volume \\
$\mathrm{C}$ & addition, left, $2,4-19 \mathrm{~s}$ \\
$\mathrm{D}$ & original, left, $2,7-22 \mathrm{~s}$ \\
$\mathrm{E}$ & original, right, $2,3-21 \mathrm{~s}$ \\
\hline \hline
\end{tabular}




\section{S2. Parameter Selection (training data for the SVM, channel and feature set)}

channel: probe positions on the right or left forehead

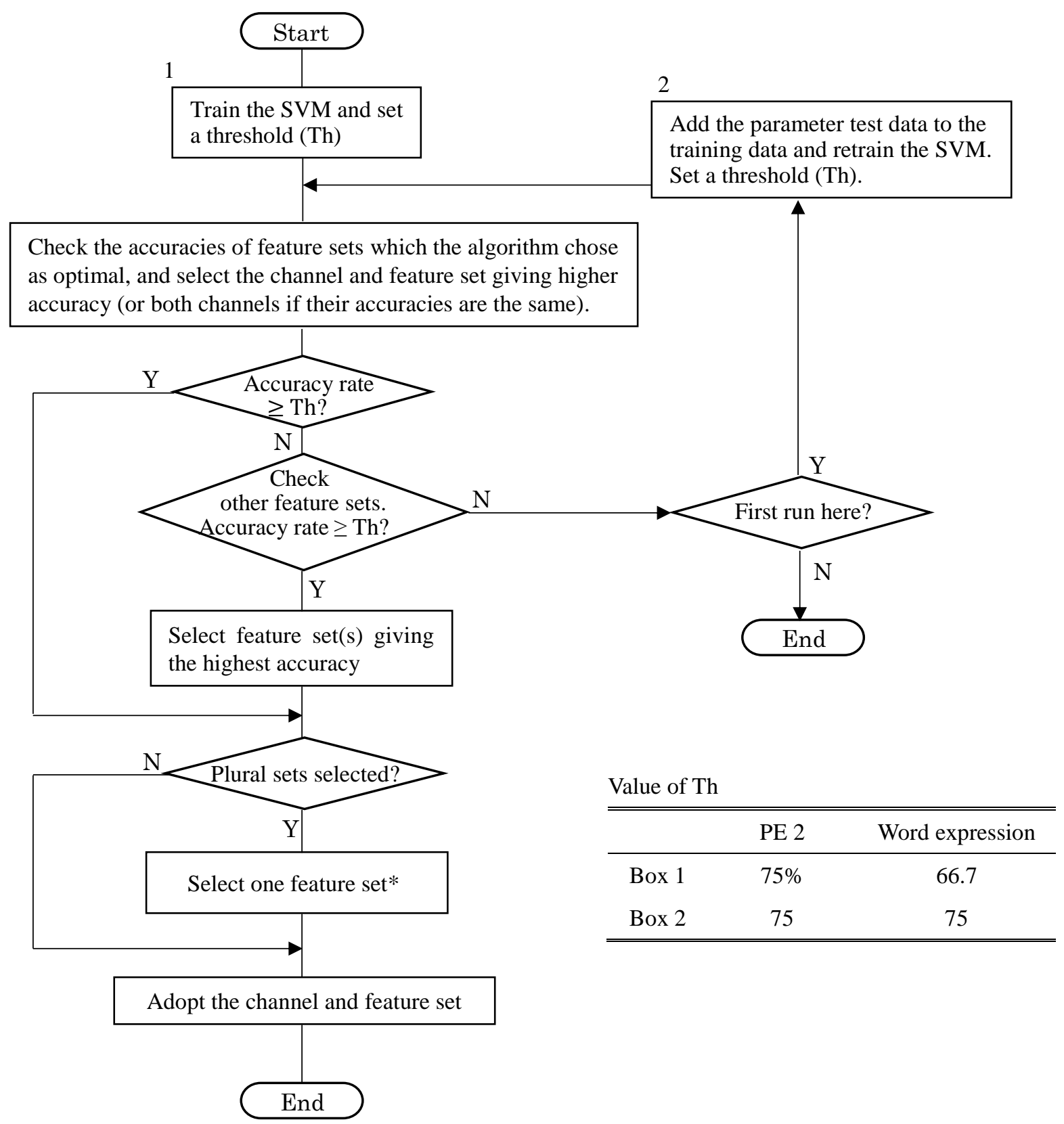

*: If there are multiple selected channels and feature sets, reduce them each to one by applying the following criteria successively: (a) the balance of "yes/no" answers to the test data, (b) the "yes/no" separation of the training data, and (c) the geometric margin.

Fig. S2. Flowchart of parameter test in II. Methods, D. Experiments. 
S2.1 Results of Parameter Test in PE 2

Parameter selection in PE 2. Numerical values represent the classification accuracy of parameter test.

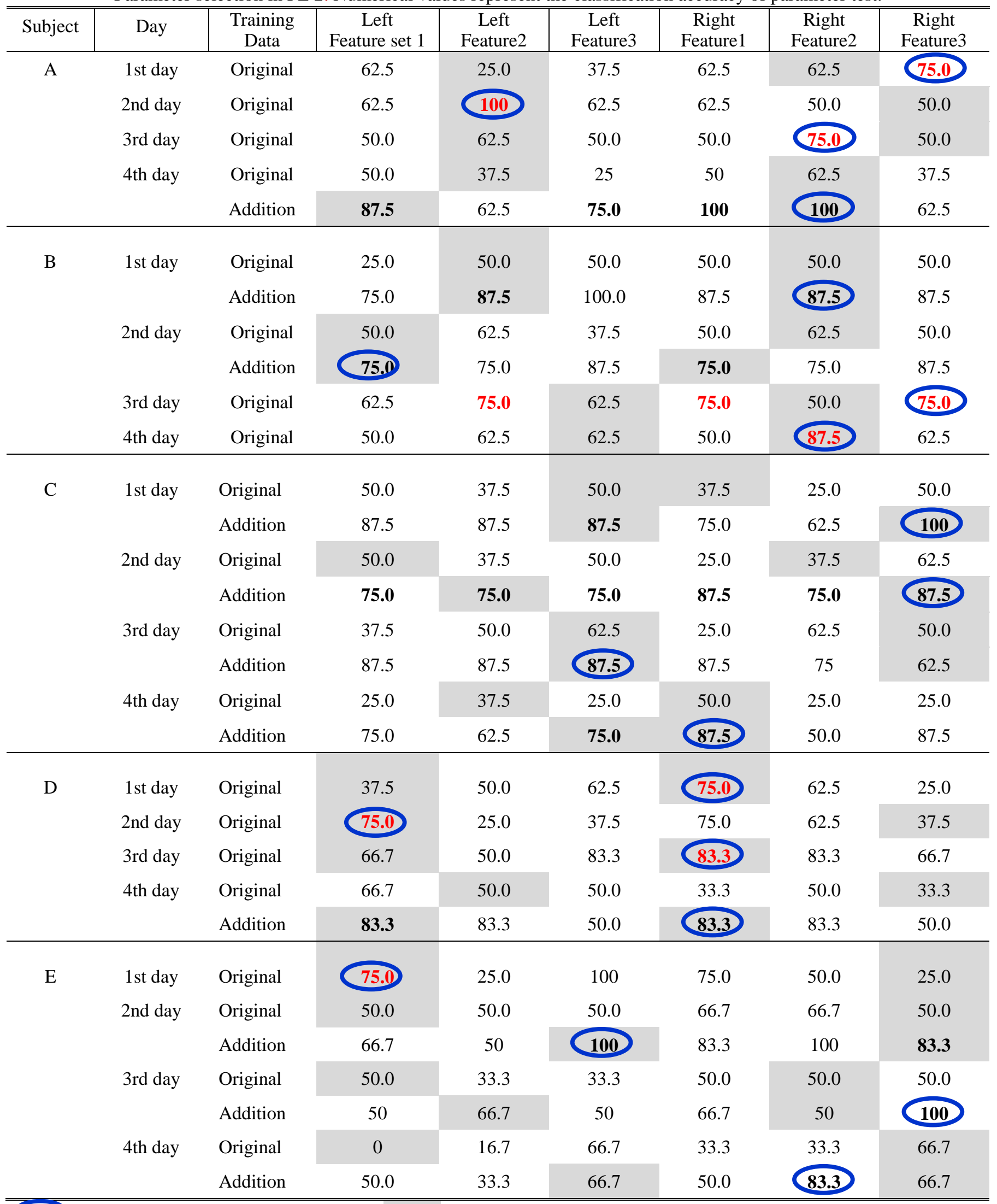

: Adopted forehead side and feature set. $\quad$ : Feature set chosen as optimal by the optimization algorithm.

Red boldface: accuracy $\geq$ Th in the case of "Original." Black boldface: accuracy $\geq$ Th in the case of "Addition." 
Table S2.2.

Reduction of channels (side of forehead) and feature sets each to one when multiple of them were selected.

\begin{tabular}{|c|c|c|c|c|c|}
\hline Subject & Day & $\begin{array}{c}\text { Training } \\
\text { Data }\end{array}$ & Accuracy & $\begin{array}{l}\text { Forehead side and feature set } \\
\text { (Y/N balance*, Y/N Separation of training data, Geometric margin) }\end{array}$ & Selection \\
\hline \multirow[t]{7}{*}{ B } & 1 st & Addition & $87.5 \%$ & L, FS2 $(2,85.7 \%, 0.0198)$ & \\
\hline & & & & R, FS2 $(2,85.7 \%, \mathbf{0 . 0 3 2 2})$ & $\sqrt{ }$ \\
\hline & 2nd & Addition & 75 & L, FS1 (0) & $\sqrt{ }$ \\
\hline & & & & R, FS1 (2) & \\
\hline & $3 \mathrm{rd}$ & Original & 75 & L, FS2 $(2,83.3 \%,-)$ & \\
\hline & & & & $\mathrm{R}, \mathrm{FS} 1(2,100 \%, 0.0550)$ & \\
\hline & & & & R, FS3 $(2,100 \%, \mathbf{0 . 0 5 9 4})$ & $\sqrt{ }$ \\
\hline \multirow[t]{2}{*}{$\mathrm{D}$} & 4th & Addition & 83.3 & L, FS1 $(1,83.3 \%, 0.0200)$ & \\
\hline & & & & R, FS1 $(1,83.3 \%, \mathbf{0 . 0 3 1 8})$ & $\sqrt{ }$ \\
\hline
\end{tabular}

*: $\mathrm{Y} / \mathrm{N}$ balance $=\mid$ number of correct "Yes" - number of correct "No"|; 0 is the best, 1 is the second best, 2 is the third best. 
S2.2 Results of Parameter Test in Word-expression Experiments

Table S2.3.

Parameter selection. Numerical values represent the classification accuracy of parameter test.

\begin{tabular}{|c|c|c|c|c|c|c|c|c|}
\hline Subject & $\begin{array}{l}\text { Session } \\
\text { (Day) }\end{array}$ & $\begin{array}{c}\text { Training } \\
\text { Data }\end{array}$ & $\begin{array}{c}\text { Left } \\
\text { Feature1 }\end{array}$ & $\begin{array}{c}\text { Left } \\
\text { Feature2 }\end{array}$ & $\begin{array}{c}\text { Left } \\
\text { Feature3 }\end{array}$ & $\begin{array}{c}\text { Right } \\
\text { Feature1 }\end{array}$ & $\begin{array}{c}\text { Right } \\
\text { Feature2 }\end{array}$ & $\begin{array}{c}\text { Right } \\
\text { Feature3 }\end{array}$ \\
\hline \multirow[t]{2}{*}{ A } & $\begin{array}{l}\text { Word Expression } \\
\text { (3rd day) }\end{array}$ & Original & 50.0 & 50.0 & 100 & 25.0 & 50.0 & 25.0 \\
\hline & $\begin{array}{c}\text { Confirmation } \\
\text { (4th day) }\end{array}$ & Original & 33.3 & 66.7 & 50.0 & 50.0 & 50.0 & \\
\hline \multirow[t]{2}{*}{ B } & $\begin{array}{l}\text { Word Expression } \\
\text { (1st day) }\end{array}$ & Original & 25.0 & 50.0 & 75.0 & 25.0 & 25.0 & \\
\hline & $\begin{array}{c}\text { Confirmation } \\
\text { (3rd day) }\end{array}$ & Original & 75.0 & 25.0 & 75.0 & 100 & 0 & 75.0 \\
\hline \multirow[t]{3}{*}{$\mathrm{C}$} & $\begin{array}{l}\text { Word Expression } \\
\text { (3rd day) }\end{array}$ & Original & 83.3 & 50.0 & 50.0 & 33.3 & 66.7 & \\
\hline & Confirmation & Original & 50.0 & 50.0 & 33.3 & 50.0 & 50.0 & 33.3 \\
\hline & (4th day) & Addition & 50.0 & 83.3 & 66.7 & 33.3 & 50.0 & 50.0 \\
\hline \multirow[t]{3}{*}{$\mathrm{D}$} & Word Expression & Original & 50.0 & 50.0 & 50.0 & 50.0 & $66.7^{\dagger}$ & 50.0 \\
\hline & (2nd day) & Addition & 66.7 & 50.0 & 83.3 & 66.7 & 66.7 & \\
\hline & $\begin{array}{c}\text { Confirmation } \\
\text { (3rd day) }\end{array}$ & Original & 50.0 & 83.3 & $66.7^{\dagger \dagger}$ & 50.0 & 33.3 & 50.0 \\
\hline \multirow[t]{2}{*}{ E } & $\begin{array}{l}\text { Word Expression } \\
\text { (3rd day) }\end{array}$ & Original & 50.0 & 33.3 & & 50.0 & 66.7 & 50.0 \\
\hline & $\begin{array}{c}\text { Confirmation } \\
\text { (4th day) }\end{array}$ & Original & 75.0 & 50.0 & 75.0 & 75.0 & & 75.0 \\
\hline
\end{tabular}

The value of Th in Fig. S2: 66.7\% in Box 1 and 75.0\% in Box 2.

†: The other accuracies were all as low as $50.0 \%$, which seemed that the original SVM training data were not good. Therefore, we added the parameter test data to it and retrained the SVM. This is equivalent to setting Th in Box 1 to $75 \%$.

$\dagger$ : The value of Th in Box 1 was left at the previous day's value of $75 \%$, and this case was not selected.

Red boldface: accuracy $\geq \mathrm{Th}$ in the case of "Original." Black boldface: accuracy $\geq \mathrm{Th}$ in the case of "Addition."

Table S2.4. Reduction of channels (side of forehead) and feature sets each to one when multiple of them were selected.

\begin{tabular}{|c|c|c|c|c|c|}
\hline Subject & Day & $\begin{array}{c}\text { Training } \\
\text { Data }\end{array}$ & Accuracy & $\begin{array}{c}\text { Forehead and feature set } \\
\text { (Y/N Balance, Y/N Separation of training data, Geometric margin) }\end{array}$ & Selection \\
\hline \multirow[t]{2}{*}{ A } & 4 th & Original & $66.7 \%$ & L, FS2 (2) & \\
\hline & & & & R, FS3 (0) & $\sqrt{ }$ \\
\hline \multirow[t]{2}{*}{$\mathrm{B}$} & $1 \mathrm{st}$ & Original & 75 & L, FS3 $(1,100 \%, 0.0678)$ & \\
\hline & & & & R, FS3 $(1,100 \%, \mathbf{0 . 0 7 2 3})$ & $\sqrt{ }$ \\
\hline \multirow[t]{2}{*}{$\mathrm{D}$} & 2nd & Addition & 83.3 & L, FS3 $(1,75.0 \%)$ & \\
\hline & & & & R, FS3 $(1,91.7 \%)$ & $\sqrt{ }$ \\
\hline
\end{tabular}




\section{S3. Example of an Expressed Word obtained through the Special Dictionary with Vowel} Entries

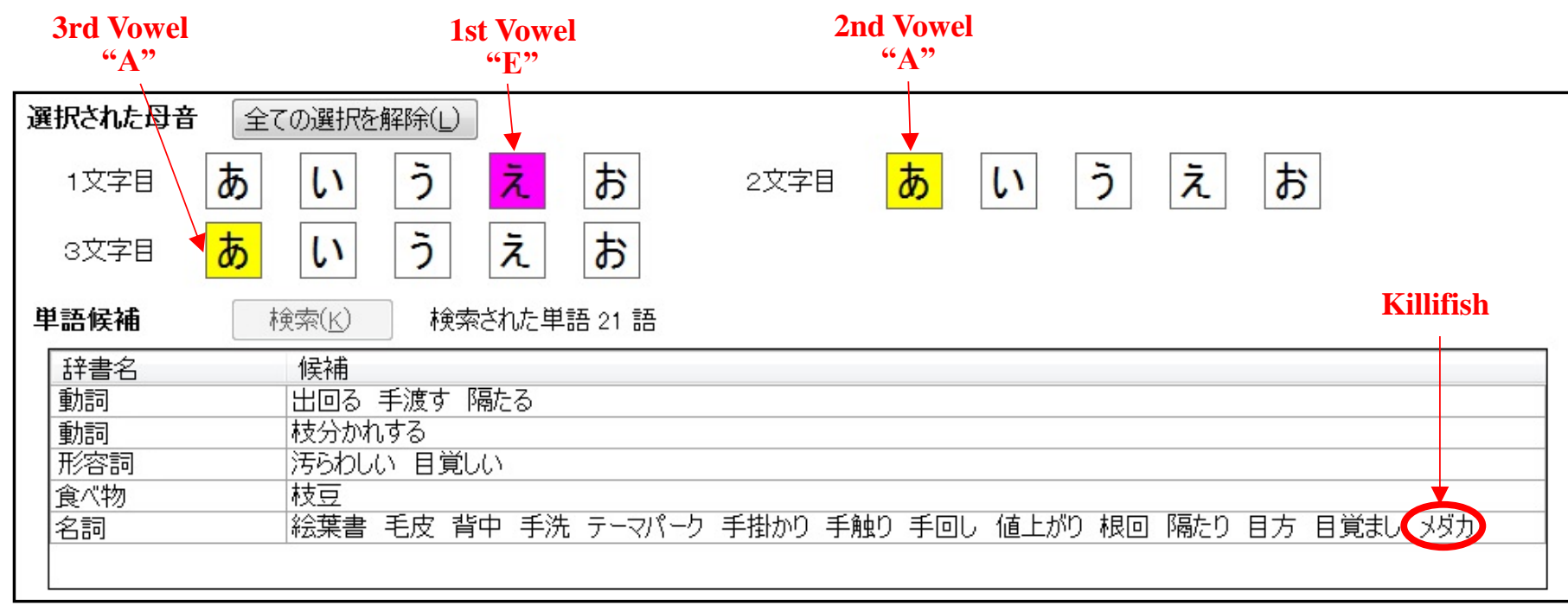

Fig. S3. Candidate words obtained by inputting three vowels "E," "A," and "A." The partner consulted the dictionary by entering the three vowels, and the dictionary returned candidate words. Among all candidate words, only "Killifish" was an animal. 